TESCHE, L. Turnen: transformações de uma cultura corporal europeia na América. ljuí: Unijuí, 2011.

\title{
CORPO, CULTURA E EDUCAÇÃO NA VIRADA DO SÉCULO XIX AO XX: O TURNEN EM QUESTÃO
}

Carlos Herold Junior*

Leomar Tesche é professor no curso de Educação Física da Universidade Regional do Oeste do Rio Grande do Sul (Unijuî). Tendo como um de seus interesses a pesquisa sobre a história da educação do corpo e da educação física, ele é o organizador de Turnen: transformações de uma cultura corporal europeia na América. O movimento ginástico iniciado por Friedrich Ludwig Jahn (1778-1852) é posto em evidência por meio da importância formativa que possuiu e de sua inserção no processo de construção da nacionalidade alemã acicatado pela necessidade de um "fortalecimento" para fazer frente à expansão napoleônica no início do século XIX.

A obra reúne quatro capítulos que focalizam o surgimento do Turnen na Alemanha e sua expansão no Brasil e Estados Unidos. Além do capítulo redigido por Tesche, lemos os demais capítulos elaborados por estudiosos alemães, especialistas na temática.

No capítulo 1, "Turnen na Alemanha: do movimento nacional de uma cultura física e motora ao moderno movimento do esporte de lazer", elaborado por Michael Krüger,' lemos uma abordagem panorâmi-

\footnotetext{
* Doutor em Educação pela Universidade Federal do Paraná (UFPR); Professor do Departamento de Educação Física da Universidade Estadual de Maringá (UEM) E-mail: carlosherold@hotmail.com.
} 
ca do surgimento e do desenvolvimento do Turnen. Ao focalizar a passagem dos "jogos selvagens"(p.15) ao "turnen escolar" no fim do século XIX, passando pela perda de espaço da prática quando relacionada a "outros modelos físicos e motores" no século XX, é enfatizado que o Turnen está no cerne de importantes perspectivas: não mais atuar como um conjunto de práticas corporais marcadas pelo papel que tiveram nos mecanismos de diferenciação nacional alemã, como ocorrera em suas origens, mas na assunção de um papel como prática integrativa, o que poderá gerar o potencial de elevá-lo à consideração de um "esporte europeu e universal" (p.46).

Tendo como título "Moças e mulheres no movimento de Turnen alemão: dos inícios até a república de Weimar", Gertrud Pfister apresenta análises sobre as diferentes formas de segregação/integração das mulheres na prática do Turnen. Ela estuda tanto as justificativas "científicas" para o veto à participação das mulheres quando essa participação passou a ser reivindicada, assim como aborda o longo processo de alteração de diretivas e procedimentos relativos às práticas e à organização do movimento para incorporação das mulheres. Costurada de forma a frisar a sujeição da problemática à situação social e política da mulher nos oitocentos e nos albores dos novecentos, a reflexão evidencia a relevância das práticas corporais, de forma geral, e do Turnen, em particular, para as lutas pela manutenção/subversão dos papéis sociais atribuídos aos homens e às mulheres. Afinal, permitir às mulheres o acesso a uma prática pensada, também, para o desenvolvimento da virilidade, era avaliado como uma agressão aos valores do século, um momento em que "palidez, desamparo e desmaio eram sinal de elegância" (p.53) e correção femininas. O capítulo mostra como o Turnen chega às escolas femininas alemãs, quais foram os cuidados com os movimentos em si ("cabeça erguida, pernas para baixo e fechadas" (p.55), bem como a dissensão sobre o fato de as sessões praticadas por mulheres serem assistidas ou serem praticadas longe dos (curiosos) olhos do público (p.55).

Pensando a expansão do Turnen no Brasil, Leomar Tesche inicia seu capítulo - “Turnen: um símbolo identitário no Brasil” - fazendo considerações sobre a "ebulição migratrória" (p.81) que aconteceu no contexto brasileiro na segunda metade do século XIX. Debruçando-se sobre o Rio Grande do Sul, investiga a presença de legionários alemães contratados para lutarem contra a Argentina em 1851. Chamados de 
Brummer, esses legionários "foram elementos importantes na Colônia, pois contribuíram para o desenvolvimento e também na manutenção da germanidade" (p.93). Causa e resultado dessa "manutenção" foi a expansão do Turnen, estudada com riqueza de detalhes por Tesche em uma reflexão que se ocupa do período compreendido entre o fim do século XIX e as quatro primeiras décadas do século XX. Ao concluí-la, Tesche endossa a importância do Turnen como um "veículo preservador" (p.145) da cultura alemã.

Annette R. Hofmann ${ }^{3}$ fecha o livro com o capítulo "Uma mente sã num corpo são': o movimento do turnen teuto-americano". Assumindo os Estados Unidos como um país que aglutinou, em sua base histórica, a presença de imigrantes de várias nacionalidades, a pesquisadora nota que, em solo americano, houve um processo mais intenso de "americanização dos alemães" (p.119) e/ou de "assimilação dos turners" (p.123). Importante para isso foi a participação dos imigrantes alemães nas lutas políticas da história americana. Interessante notar que essa presença alemã, na história americana, entre outras coisas, foi possibilitada por uma "despolitização do turnen (p.119), entendendo esse processo como uma desvinculação entre os movimentos praticados e o contexto no qual eles se originaram. Para Hofmann, foi isso que encetou a grande importância do Turnen nos Estados Unidos, materializada em sua inserção na estrutura educacional daquele país. Esse fato acelerou, ainda mais, a americanização dos imigrantes alemães, sobretudo, depois de terem sofrido as pressões de uma "histeria antialemã" (p.123), que assolou várias partes do mundo na segunda década do século XX, não sendo diferente do que se viu em solo norte-americano. Por fim, depois de apresentar alguns fatos sobre o Turnen na atualidade dos Estados Unidos, Hofmann arremata dizendo que, nas festas ginásticas que hoje lá ocorrem, apesar de "seus nomes e história, pouco têm a ver com a cultura alemã” (p.127).

Vale salientar que a relevância de uma obra sobre as bases alemãs da ginástica e sua expansão interessa não apenas a quem se dedica a realidades em que essa prática surgiu e floresceu de forma mais visível, como ocorreu no sul do Brasil, por exemplo. Como bem lembra Roland Renson $^{4}$ na introdução da obra, "junto com as ginásticas suecas e os esportes britânicos, o turnen alemão formou um dos três 'pilares da sabedoria corpórea dos séculos 19 e 20”' (p.11). 
A leitura do conjunto dos capítulos permite inferir que a origem e a expansão do Turnen pela Alemanha e pelo mundo estiveram fortemente relacionadas com ambições formativas, tanto as especificamente escolares, quanto as que aconteceram socialmente e ligadas à dialética de preservação/transformação de culturas diferentes, conectando-se à medida que as forças políticas e sociais então em jogo levavam ao cruzamento das fronteiras. Como exemplos a evidenciar essa constatação, temos os diferentes desdobramentos da expansão e recepção do Turnen que ocorreram no Brasil e nos Estados Unidos. Todavia, essas diferenças acabaram ocupando um lugar incidental no livro, mesmo que elas, de alguma forma, sejam sinalizadas com destaque no título da coletânea. As análises aumentariam sua capacidade de diálogo com os atuais encaminhamentos da pesquisa sobre a história educacional dedicada à educação do corpo, se estudassem, de forma mais detalhada, os mecanismos de criação do Turnen junto às diferentes apropriações e transformações a que estão sujeitas as ideias, as práticas e as instituições educacionais. Se a ideia de "raízes europeias" (SOARES, 1994), no que tange à educação do corpo e à educação física, ainda tem grande valor para o estudo da história dessa dimensão educacional, do ponto de vista heurístico, uma "análise menos esquemática dos intercâmbios entre as culturas" (p.18) pode levar a uma indagação mais cuidadosa da "relação centro-periferia" no processo de "circulação de saberes, ideias, concepções e indivíduos" (TABORDA DE OLIVEIRA; BELTRAN, 2013, p.17). Pode, também, proporcionar aos estudiosos da história do corpo e de sua educação o contorno de "perigos políticos e intelectuais de radicar os primórdios das formas educativas em um tempo ou espaço unívoco" (TABORDA DE OLIVEIRA; BELTRAN, 2013, p.18).

A obra organizada por Leomar Tesche não incorre nesses "perigos", mas evidencia a existência deles, com alguma hesitação sobre a ciência do tormento e das limitações que podem vitimizar os historiadores da educação que não observam a advertência feita por Taborda de Oliveira e Beltran (2013). Todavia, mesmo não assumindo esse cuidado até as últimas consequências, o livro mostra uma porta analítica e temática, deixando abertas muitas oportunidades para se estudar o corpo na história.

Além dessas oportunidades, o valor da obra reside no eloquente endosso da relevância que a prática corporal em questão teve na construção dos traços socioculturais de um determinado tempo e de vários espa- 
ços. Isso também é um estimulante muito valioso para o campo da história da educação e educação física, pois ajudará outras pesquisas a demonstrarem o mesmo em outras épocas e/ou com outras práticas. Dito de outro modo, em que pese a especificidade e a unidade temáticas da coletânea, bem como a não realização de todas as positividades metodológicas que a própria obra enceta, para quem se interessa pela história do corpo, das práticas corporais e da educação física, Turnen poderá servir como uma importante sustentação na hora de justificar esforços de pesquisa voltados aos estudos históricos sobre a cultura corporal de movimento existente na virada do século XIX ao XX. Embora esse período congregue um bom número de pesquisadores da história educacional brasileira, a dimensão corporal dessa educação ainda tem espaço para receber maiores e mais detidas reflexões.

Consoantemente a essa observação, Turnen também é importante por reunir no conjunto de seus capítulos uma quantidade generosa de referências bibliográficas produzidas em vários países e que investigam as variadas facetas do Turnen em termos mundiais. Informações valiosas para que, no futuro, pesquisadores brasileiros somem esforços aos de Leomar Tesche e se ocupem de dimensões ainda não estudadas sobre a expansão dos movimentos ginásticos no Brasil.

É importante registrar que a coletânea é apresentada em uma edição bilíngue (português-alemão), o que sinaliza seu potencial de integração entre pesquisadores de vários continentes: um esforço editorial a ser parabenizado por permitir uma difusão mais ampla das reflexões e uma colaboração mais intensa no necessário esforço multiplicador que cada pesquisa deve possuir. Sem desconsiderar o esforço do organizador e do editor ao abraçarem essa opção, embora a leitura do livro seja tranquila, no registro linguístico dos capítulos traduzidos do alemão, nota-se a necessidade de algumas escolhas da tradução terem sido mais aproximadas do português tal como se fala e se lê no Brasil. Sem comprometimentos à compreensão das análises, esse detalhe perturba (apenas um pouco) a leitura, que, nos demais aspectos formais e temáticos, é muito estimulante.

Tendo em mente todas essas ponderações, as possibilidades temáticas e teóricas encetadas por Turnen, de Leomar Tesche, devem ser incorporadas às pesquisas em história da educação física que ocorrem no Brasil e nos demais países de língua portuguesa e alemã. 


\section{NOTAS}

1 Professor da Westfälischen Wilhelms-Universität, Münster, Alemanha.

2 Professora do Departamento de Ciência do Exercício, Universidade de Copenhague, Dinamarca.

3 Professora do Departamento de Esportes da Universidade Pedagógica de Ludwigsburg, Alemanha.

4 Professor da Faculdade de Cinesiologia e Ciências da Reabilitação, Universidade Católica de Louvain, Bélgica.

\section{REFERÊNCIAS}

SOARES, C. L. Educação Física: raízes europeias e Brasil. Campinas: Autores Associados, 1994.

TABORDA DE OLIVEIRA, M. A.; BELTRAN, C. X. H. Uma educação para a sensibilidade: circulação de novos saberes sobre a educação do corpo no começo do século XX na Ibero-América. Revista Brasileira de História da Educaşão, Campinas, v.13, n.2 (32), p.15-43, maio/ago. 2013. Disponível em:

http://www.rbhe.sbhe.org.br/index.php/rbhe/article/view/346/pdf. Acesso em: 06 set. 2013. 